\title{
Inter-Group Disparities in Fatal Road Traffic Accident in Texas
}

\author{
Ayodeji Iyanda, MSc. \\ Department of Geography, Texas State University, \\ San Marcos, Texas, USA
}

Doi:10.19044/esj.2018.v14n17p61 URL:http://dx.doi.org/10.19044/esj.2018.v14n17p61

\begin{abstract}
The risk of dying from a road accident is higher than dying from heart and infectious diseases. Mortality and injury related to fatal accident is increasing partly due to the level of motorization. Further, the associated risk of accident varies among diverse population groups. This study examines the inter-group difference in injury and mortality caused by road accident in Texas using Fatality Analysis Reporting System (FARS), the nation's most comprehensive population-based accident database from 2014 to 2016. Texas had the highest accident mortality in 2016 making accident the fifth leading cause of death. This study performed two main tasks: 1) It analyzed injury severity variation for different age groups using data mining technique. 2) Accident fatality disparity was determined by using both nonparametric version of analysis of variance and multilevel binary logistic regression. The study interprets fatality risk using the odd ratio. Result shows that Asian subgroups, European Spanish, Central and South Americans, and children were at greater risk. This study is important for culturally specific public health intervention design targeting the most vulnerable subgroups based on people's cultural orientation.
\end{abstract}

Keywords: Fatal traffic accident, inter-group disparity, population health, minority groups, Texas

\section{Introduction}

Road traffic accidents (RTAs) are a leading cause of many sudden deaths and lifelong injuries worldwide (World Health Organization [WHO], 2017). In 2015, 1.3 million people died through road accident of whom $76 \%$ were men and boys (WHO, 2017). In the same year in the US, total fatalities were 35,485 while victims of accident related injuries were about 2.5 million. The economic and comprehensive costs were $\$ 242$ billion and $\$ 836$ billion, respectively (Blincoe, Zaloshnja, \& Lawrence, 2015). Increasing 
number of daily trips per vehicle miles travel (MVT) and vehicle volume per year contribute to high incidence of motor accident (National Highway Traffic Safety Administration, 2017). Scarce knowledge exists on how fatal injury leading to death vary among different age and cultural minority subgroups in Texas.

Previous studies have revealed that accident risk exposure and outcomes depend on many complex factors such as personal behavior (Sümer, 2003; Tao, Zhang, \& Qu, 2017), safety compliance and policies (Han, Newmyer, \& Qu, 2017; Wolf et al., 2017), socio-economic status (Braver, 2003), emergency response system and pre-existing health conditions (Lu \& Davidson, 2017; Rupp et al., 2013). There is no consensus on factors contributing to risk disparity among diverse groups especially in the US with high cultural diversity. At the national level, studies have been conducted to compared state level accident risk which conceal small level risk within a lower geography. Since aggregated studies are liable to ecological fallacy (Briggs et al., 2005, 2006; Factor, Williams, \& Kawachi, 2013; Wolf et al., 2017), it is germane to examine the inter-group disparity in traffic-induced mortality at smaller geographic scale.

\section{- Research problem}

Studies have shown that teenagers (15-19) and the older (65 and above) drivers are more vulnerable to fatal road accident (Ang, Chen, \& Lee, 2017; Chong et al., 2017), however, these studies have not shown the risk for children occupants (0-15). Texas child mortality rate of 18.1 per 100,000 is higher than the national average of 16.8. The teen death rate in Texas is 50.7 which is slightly lower than the US teen rate of 51.2 (www.worldlifeexpectancy.com/usa/texas-teen-death-rate). Yet, limited research exists on the contribution of road accident to children and teen mortality (Wolf et al. 2017). Further, in Texas there is no outstanding research on the vulnerability of some ethnic minority groups involved in fatal road traffic accident.

Texas has the highest number of fatal accident $(3,407)$ and deaths $(3,776)$ in 2016 , a $5.45 \%$ increase compared to 2015 traffic accident death (Texas Department of Transportation, 2017). Inter-group variation exists among people of different sexes, cultural groups, age groups, and social classes (Factor, Mahalel, \& Yair, 2008; Ma, Hussain, \& Abbe, 2017). The National Highway Traffic Safety Administration (NHTSA) show that racial and ethnic minorities are mostly impacted (Hilton, 2006). Specifically, the percentage of Hispanics and Asian population is increasing as well as the level of accident fatality among these minority groups. Many studies have examined the disparity in the risk of road accident among Hispanic groups but usually categorize other ethnic groups under one generalize term, 
'Others'. Risk level for these groups classified as 'Others' is always masked. Few studies have examined the minority groups in the state of Texas which has the highest rate of accident occurrence.

The purpose of this study is to examine how risk of dying in fatal traffic accident vary between sociocultural groups-define as Hispanic origin and racial groups (Factor et al., 2008). In addition, disparity in injury severity recorded in a fatal accident was also examined among different age groups. Knowledge from the study will expand our understanding of intergroup variation in fatal road accident. Outcome of the study will help in designing culturally specific public health intervention targeting the most vulnerable subgroups based on people's cultural orientation.

\section{○ Related literature and theoretical framework}

This study uses two complementing theories to understand fatal road accident in relation to inter-group risk. Figure 1 presents how sociocultural and socioeconomic factors are associated with road traffic accident and the resultant outcomes, death/injury. Risk-compensation theory, developed by a Canadian psychologist (Wilde, 1982), posits that drivers assume certain level of acceptable risk based on some predetermined cost and benefit of their actions. The propensity to take risk increases with impulsivity, sensationseeking, and attitudes toward dangerous driving but dissipates with age (Richer \& Bergeron, 2012). Further, the increasing confidence in the automotive technology and improvement in the safety measures triggers people's behavior to engage in risky driving. Despite the use of seat belt, automatic braking systems (ABS), cruise control, protective head gear for motorcyclist, baby's car seat, and other safety measures, deaths and injuries from road accident still persist (Wilde, 2009). Reason for the continuous risky behavior is still not known.

Social resistance theory (SRT) argues that non-dominant minority groups are prone to behave in a certain manner in opposition to dominant group expectations or against the law of the land (Factor, Kawachi, \& Williams, 2011). The theory proposed that most minority groups tend to act unlawfully and they develop everyday resistance practices that include various unhealthy behaviors. As it appears in Figure 1, some behaviors such as breaking traffic laws, abuse of drug and alcohol are common resistance practices among non-dominant minorities. Factor et al. (2013) conducted a pilot study to test some of the hypotheses proposed earlier in their paper in 2011. They noted that the minority groups are more likely to be involved in various unhealthy behaviors such as smoking, drinking, and non-use of seat belt. Elias et al. (2016) conducted a study to determine the traffic behavior in a single minority group but their findings did not support the premise of 
resistance theory, rather daily trip was the main mechanism for traffic violation between offenders and non-offenders.

Risk culture varies geographically among countries and within a country. Sociologist defined culture as the 'knowledge, beliefs, art, ethics, law, and all other abilities and habits necessary for a person to be a member of society' (Factor, Mahalel, \& Yair, 2007). Cultural background influences how people behave in a society. Past studies affirmed that cultural differences among drivers have varying implications in terms of driving behavior and accident risk (Hayakawa, Fischbeck, \& Fischhoff, 2000; Herrero-Fernández et al., 2016; Özkan, et al., 2006).

Accident prevention is at the fore-front of public health campaign aims to improve quality of life. However, it is hard to control people's behavior because of the lack of cultural homogeneity and human irrational behavior. Taking cognizance of cultural background in designing accident prevention strategy will translate to life saving outcome while effort to overlook it can lead to continuous accident trend (Factor, Mahalel, \& Yair, 2007). In many times, lack of comprehensive traffic data hampers in-depth understanding of some important causes of road accident (Bedard, Guyatt, Stones, \& Hirdes, 2002). Public accessible accident data do not reveal detail background information about victim of fatal road accident. Consequently, researchers pay less attention to culturally acquired/shared behavior that can influence fatal road accident. Understanding the influence of cultural background among accident victims can unveil group vulnerability (Briggs et al., 2005; Factor et al., 2011a, 2013).

Traffic law compliance differs among diverse groups. Some groups of people tend to respect the law more than others; thereby they tend to have lower level of risk (Elias, Blank-Gomel, Habib-Matar, \& Shiftan, 2016; Factor, Kawachi, \& Williams, 2011b). Onwuachi-Saunders and Hawkins (1993) noted that traffic accident as the leading cause of injury among African-American, while in 2002, traffic accident was not the leading cause of death among this ethnic subgroup (Hamdan, 2013). Studies that show variation in accident risk among age groups indicate high risk among Hispanic children compared to White children. In a separate study, CamposOutcalt, Bay, Dellapena, and Cota (2003) found that American Indians have elevated risk compared with non-Hispanic Whites across all ages, sexes, and place of residence. Meanwhile Hispanic females across board, rural Hispanic males, and African-American men had lower risk of dying in a road accident (Campos-Outcalt, Bay, Dellapena, \& Cota, 2003). There is no clear evidence on the risk of RTA fatality for other racial and ethnic groups such as Euorpean and Asian subgroups in the US. Specifically, there is a scarce study in the US to show whether other European Spanish speakers are at higher risk compared to American Spanish speakers. 


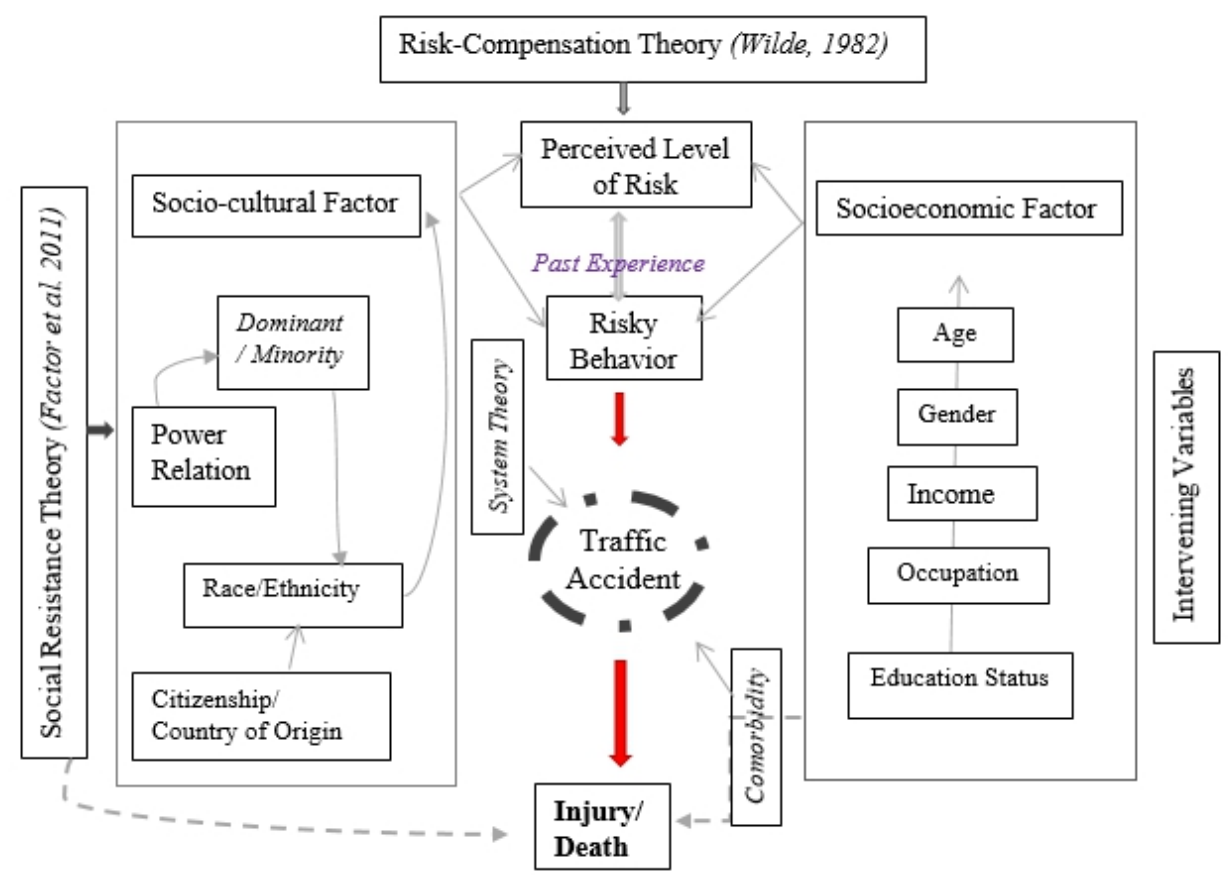

Figure 1. Road Traffic Accident Framework using Social Resistance Theory and Riskcompensation Theory.

The effect of passenger occupancy ratio and characteristics has been established in the literature. Peer driving continue to result to risky behavior such as over speeding and distracted driving. The age and the gender of both driver and passengers have high likelihood of influencing risk of accident (Behnood \& Mannering, 2017; Lee \& Abdel-Aty, 2008; Simons-Morton et al., 2011). Young male passengers riding with peer male drivers often experience traffic accident compared with female driver and passengers. Weiss, Kaplan, and Prato (2014) showed that the risk of fatal injury from RTA increases by 3, 4, 7 times when female, male and combination of both male and female are present in the vehicle among young drivers. Contrarily, Yasmin, Eluru, Bhat, and Tay, (2014) showed that vehicles that contain multiple occupants are less to be involved in severe/fatal accident in Australia.

Safety measures such as the use of seat belt also vary among racial/ethnic groups. A study that examined the use of seat belt among Hispanic subgroups compared to non-Hispanic White indicated that seat belt use was similarly prevalent (Briggs et al., 2006). The study further showed that within the Hispanic subgroups, subgroups identified as MexicanAmerican and Central American/South American (CASA) origins are more likely to use seat belt compared with Cubans and Puerto Ricans and nonHispanic Whites. In 2002, Insurance Institute for Highway Safety 
(IIHS)/Highway Loss Data Institute (HLDI) reported that the rate of safety seat belt use was lower among Black people than other racial/ethnic groups. Meanwhile, IIHS report noted that seat belt use varies among racial/ethnic groups based on primary and secondary enforcement laws.

In a state where secondary law is more grounded, Black/AfricanAmericans tend to use less seat belt compared with a state operating primary laws (Wells, Williams, \& Farmer, 2002). Regardless of race/ethnicity, seat belt use was significantly higher in primary law state (Insurance Institute for Highway Safety (IIHS), 2002; Wells et al., 2002). Earlier studies found no significant difference among race/ethnicity for seat belt usage among Blacks, Whites and Hispanics drivers involved in fatal accident (Daniel, Bladikas, \& Curley, 2007; Wells et al., 2002). Study on children (0-15 years) involvement in fatal road traffic accident found that difference in state policy on red- light camera and restraint use had significant influence on risk of fatality in the US (Wolf et al., 2017). There has not been a consistent result of safety measures among race/ethnicity in accident literature. This study answers these research questions. 1) How does injury severity vary among age groups involved in fatal road accident in Texas? 2) Does the risk of dying in a fatal accident differ between age groups, race, and ethnicity? 3)Which subgroup of race and ethnicity is more vulnerable to accident fatality in Texas? 4) Do Age, gender, speeding behavior, and season moderate the risk of racial and ethnicity groups in fatal road accident?

\section{- Data and Method}

\section{- Data description and variables}

This paper analyzed person-level fatal accident data in Texas. Fatality Analysis Reporting Systems (FARS) data primarily contains reported cases of fatal accident that resulted in death of at least one person within 30 days of accident event. It is a unified database that stores accidents events for the entire United States and publicly available online (https://wwwfars.nhtsa.dot.gov). Cases of accident are reported from different sources such as police compilations at state level, death certificates from the hospitals, state driver licensing offices, and from other vital register sources. The accident records are being managed and collated by the national highway traffic safety administration (NHTSA) with its head office seating in Washington DC. Not until 1999 that data on race and ethnicity information was collected alongside fatal accident data. FARS data has been described and recommended for study of accident victim minorities because of its methodological advantages over other sources of fatality data from trauma centers (Briggs et al., 2005).

The database does not report any traceable personal information such as address or name due to confidentiality. As a result, it does not need the 
permission of internal review board. Query tool was available to search for different options on crash records, people, and vehicle. There are three categories of accident data. The first option allows for occupants and nonoccupants information but not vehicle or driver level information. The second option is available for bicyclist, pedestrian and other road users that are not occupying the vehicle at the time of accident. Vehicle and driver level information is not available for this option as well. The third option is more detailed and was selected for the purpose of this study. This option allows for information on motor vehicle occupants (driver and passengers), environmental variables, vehicle characteristics, race and ethnicity, and other behavioral variables. The fatality data for 2014, 2015, and 2016 was combined for this analysis and contain 7695, 7710 and 8112 accident victims, respectively.

\section{- Variable measures and test}

The primary dependent variable measured was the number of fatality in a traffic accident which was a continuous variable. It was dichotomized $(1=$ 'died' and $0=$ 'not die') to suit the third and fourth research questions. The second dependent variable used was the injury severity with four injury levels (BACK): B is 'minor injury', $\mathrm{A}$ is 'major injury', $\mathrm{C}$ is 'possible injury' and $\mathrm{K}$ is 'fatal/severe injury'.

The primary inter-group (independent) variables assessed from FARS database are racial and ethnic groups. The race variable identifies people who are White, Black, American Indian, Asian Indian, Chinese, Japanese, Korean, Hawaiian, Filipino (recoded to 'Asian' due to small frequency), Vietnamese, Guamanian, Samoan (recoded to one group) and other mixed races. White was the reference variable in the logistic regression model. The study used Hispanic origin as a measure of ethnicity. The reported Hispanic origins reported in the database were Mexican, Puerto Rican, Cuban, Central and South American, European Spanish, others Hispanic subgroups, and non-Hispanics. The Hispanic origin were classified into five (5) categories and non-Hispanics was used as the reference group in the model. Other variables included in the variable are age, sex, vehicle occupant and month of accident recoded to seasons. These variables serve as controlling variables and were used to adjust for the primary independent variables. Age was reported as a continuous variable but was recoded into seven categories ranging from $\mathrm{c} 1={ }^{\prime} 0-5$ ', $\mathrm{c} 2={ }^{\prime} 6-15$ ', $\mathrm{c} 3={ }^{\prime} 16-25$ ', c $4=$ ' $26-35$ ', c5 '36-45', $\mathrm{c} 6={ }^{\prime} 46-55$ ', to $\mathrm{c} 7=$ ' $\geq 56$ ' years.

In line with the first research question (RQ1), a test of difference was performed based in Chi-Square test of independence. Decision tree was used to explore the level of injury fatality for different age groups (Tseng, Nguyen, Liebowitz, \& Agresti, 2005). Quick, Unbiased, and Efficient 
Statistical Tree (QUEST) algorithm is a data mining tool. 'The decision tree algorithm starts growing at the root node, and stops growing new nodes when no further splits are necessary' (Tseng et al., 2005).There were seven nodes $(\mathrm{N})$ and four terminals $(\mathrm{T})$ in the outcome. Variables with multiple classes are merged into two groups to arrive at binary splits which are determined using QDA (Quadratic Discriminant analysis). QUEST was appropriate because of one major advantage. QUEST algorithm is unbiased when splitting variable, unlike CART (Classification And Regression Tree, C\&RT) which is biased towards selecting split-variables. CART allows multiple splits and include cases with missing values. Chi-Square goodness of fit was used to examine the differences in injury severity among the age groups at $95 \%$ significant level.

For the second research question (RQ2), analysis of variance and post-hoc test was used to determine the difference between and within age groups, race and ethnicity. Multi-level binary logistic regression was modeled to answer the third (RQ3) and fourth (RQ4) research questions. Only the race and ethnicity variables were introduced in the first model. In the second model, age, seat belt use/ restraint system, season of accident, and occupancy ratio were introduced. Model fit was determined using Hosmer and Lemeshow test, a Chi-Square test. A model with p-value greater than 0.05 indicates a good model and otherwise, means poor model. Missing cases were omitted list-wisely, as a result only 7,685 (32.7\% of 23517) cases were used in Model 1 and 2,413 (10.3\%) cases in Model 2. Result interpretation was based on the odd ratio (OR) of the model coefficients, that is, the exponential form of beta coefficient, $\exp (\mathrm{B})$. This is the coefficient value in logistic regression similar to the one used in linear regression. Finally, categorical variables were presented in frequency and percentage and mean and standard deviation were reported for continuous variables. All analyses were performed in IBM ${ }^{\mathrm{TM}}$ SPSS V.20.

\section{- Result}

\section{- Univariate analysis}

Table 1 presents the descriptive summary of the variables used in this study. Between 2014 and 2016, the total number of people who were involved in a fatal accident in Texas was 23,517. This number includes drivers that drove alone and other passengers that rode with a driver including children. Among the total number of people who were involved, $68.2 \%$ died between the time of accident and within 30 days of occurrence. Four out of five of the people involved in motor vehicle accident were identified as White (83.5\%), $12 \%$ were identified as Black/AfricanAmerican. For the ethnic groups, one quarter were classified as Mexican (24.4\%), other unidentified Hispanic origins were 13.8\%, and those who 
were not classified as Hispanic were $60.1 \%$ (non-Hispaincs). One-tenth of the children between ages 0-15 were in the vehicle at the time of the accident occurrence. Majority of those involved in fatal accident used at least one type of restraint system $(71.2 \%)$ compared with those who did not use. More males $(66.8 \%)$ than females were involved in fatal road traffic accident in Texas. Most of the accidents occurred in Fall, particularly in the month of October and the least were in the Winter season. The last column in Table 1 shows the result of Pearson's Chi-square analysis. The result indicates significant differences between the categorical variables at $5 \%$ alpha level $(\mathrm{P}<0.05)$.

Table 1. Summary of variables and Chi-Square result

\begin{tabular}{|c|c|c|c|c|}
\hline & Variables & Frequency & Percentage & $X^{2}(\mathrm{df})$ \\
\hline \multirow[t]{2}{*}{ Fatality } & Died & 7710 & 32.8 & \\
\hline & Not Die & 15807 & 67.2 & $1047(1) \dagger$ \\
\hline \multirow[t]{2}{*}{ Safety Measure } & No restraint/Seat Belt & 6162 & 28.8 & \\
\hline & Restraint used & 15231 & 71.2 & $28.2(1) \dagger$ \\
\hline \multirow[t]{4}{*}{ Crash Season } & Spring & 5961 & 25.3 & \\
\hline & Summer & 6005 & 25.5 & $42(3) \dagger$ \\
\hline & Fall & 6178 & 26.3 & \\
\hline & Winter & 5373 & 22.8 & \\
\hline \multirow[t]{6}{*}{ Race } & White & 7433 & 83.5 & \\
\hline & Black & 1109 & 12.5 & \\
\hline & American Indian & 19 & 0.2 & \\
\hline & Asian & 39 & 0.4 & $21790(5) \dagger$ \\
\hline & Vietnamese/Guamanian & 41 & 0.5 & \\
\hline & Other Races/Mixed & 256 & 2.9 & \\
\hline \multirow[t]{6}{*}{ Ethnicity } & Mexican & 1882 & 24.4 & \\
\hline & Puerto Rican/Cuban & 58 & 0.8 & \\
\hline & Central/South American & 72 & 0.9 & $8621(4) \dagger$ \\
\hline & European Spanish, CASA & 75 & 1 & \\
\hline & Hispanic Others & 1061 & 13.8 & \\
\hline & Non-Hispanics & 4637 & 60.1 & \\
\hline \multirow[t]{7}{*}{ Age Class } & $0-5$ & 887 & 3.8 & \\
\hline & $6-15$ & 1515 & 6.6 & \\
\hline & $16-25$ & 5658 & 24.6 & $2450(6) \dagger$ \\
\hline & $26-35$ & 4597 & 20 & \\
\hline & $36-45$ & 3379 & 14.7 & \\
\hline & $46-55$ & 2977 & 12.9 & \\
\hline & $>=56$ & 4029 & 17.5 & \\
\hline \multirow[t]{2}{*}{ Sex } & Male & 15472 & 66.8 & $1279(1) \dagger$ \\
\hline & Female & 7692 & 33.2 & \\
\hline \multirow[t]{5}{*}{ Injury Severity } & No Apparent Injury (O) & 6385 & 27.7 & \\
\hline & Possible Injury(C) & 1839 & 8 & \\
\hline & Minor Injury(B) & 3197 & 13.9 & $7557(3) \dagger$ \\
\hline & Major Injury (A) & 2687 & 11.6 & \\
\hline & Fatal Injury(K) & 8964 & 38.9 & \\
\hline Occupancy & Occupancy & 8757 & $2.69(3.75) *$ & \\
\hline
\end{tabular}

$*$ Mean, value in parenthesis ( ) is the standard deviation; df degree of freedom; $\dagger$ asymptomatic significant level at 5\%. CASA, Central American/ South American 
○ Bivariate analysis: Quick, Unbiased, Efficient Statistical Tree

The QUEST algorithm was used to explore the first research question (Figure 2). In the first stage (Step1), the algorithm assessed the difference in injury severity among the age classes by having two groups and examined the difference in-between the groups. The first group (group 1) contains ages between 0 and 15 years which represents the first two age classes (0-5 and 615); $23 \%$ of this group sustained fatal injury, $24.5 \%$ had major injury, $30 \%$ had minor injury, and $21.7 \%$ was recorded to have possible injury. The second group contains the rest age classes (i.e. 16-25, 26-35, 36-45, 46-55, $\geq 56$ ). In this age groups, $57.2 \%$ sustained fatal injury, $15.1 \%$ had major injury, $17.7 \%$ had minor injury and only $10 \%$ from this group had possible injury. Chi-Square statistic shows a significant difference between the two groups $(\mathrm{p}<0.05)$.

The second stage (Step 2) in the analysis further examines the difference between the second group in the previous step (Step 1). People between ages 16 and 25 were selected as group 1 in this step and others as group $2(26-35,36-45,46-55, \geq 56)$. There is a statistically significant difference between group 1 and 2 in the second step $(\mathrm{p}<0.05)$. Out of the people in group 1, 51.4\% had fatal injury, $17.8 \%$ had major injury, 20.9\% had minor injury, and $9.9 \%$ was recorded to sustain possible injury. In group 2 in this step, $59.4 \%$ sustained fatal injury, $14 \%$ had major injury, $16.5 \%$ had minor injury, and $10.1 \%$ had possible injury.

In the last stage (Step 3), people that fall within 26-35 and 36-45 years are classified as group 1 while the last two age categories (46-55 and $\geq 56$ ) represent group 2 . In group 1, 54.8\% sustained fatal injury, $15.4 \%$ had major injury, $18.3 \%$ had minor injury and $11.5 \%$ had possible or slight injury. Among the older groups (i.e. group 2), 64.6\% had fatal injury, 12.6\% of them had major injury, $14.4 \%$ sustained minor injury and $8.4 \%$ had slight injury. There is a statistically significant difference between group 1 and 2 in the last stage $(\mathrm{p}<0.05)$ of QUEST analysis.

\section{- Multiple comparison analysis}

Kruskal-Wallis analysis was conducted to test for the difference in accident fatality among age groups $\left(\mathrm{H}_{(6)}=10.04\right.$, $\left.\mathrm{p}>0.05\right)$, racial groups $\left(\mathrm{H}_{(5)}=11.76, \mathrm{p}=0.038\right)$, and ethnic groups $\left(\mathrm{F}_{(5)}=78.25, \mathrm{p}<0.05\right)$. Table 2 presents the result of post-hoc test for ethnicity and age groups. There is a significant difference between Mexican and non-Hispanics $\left(\mathrm{X}^{2}=36.170, \mathrm{p}<\right.$ $0.05)$ and between Hispanic 'Others' and non-Hispanics $\left(\mathrm{X}^{2}=13.56, \mathrm{p}<\right.$ $0.05)$. There are significant differences between $0-5$ and five other age groups, it is so between age group 6-15 and four other age groups (please refer to Table 2 for statistical details). 


\section{- Multivariate logistic regression analysis}

In the multivariate analysis, two models were developed to assess the disparity in fatal road accident among different cultural groups (Table 3). First model uses only race and Hispanic origin (ethnicity) as primary independent factors. The model shows that Black/African-Americans, Puerto Ricans/Cuban, and 'Other' Hispanics were 33\%, 34\%, 39\% significantly less likely to die in a fatal accident, respectively. Meanwhile, American Indians were three times more likely to die compared with other mixed races in the reference group (OR=3.1; CI 0.69-13.65).

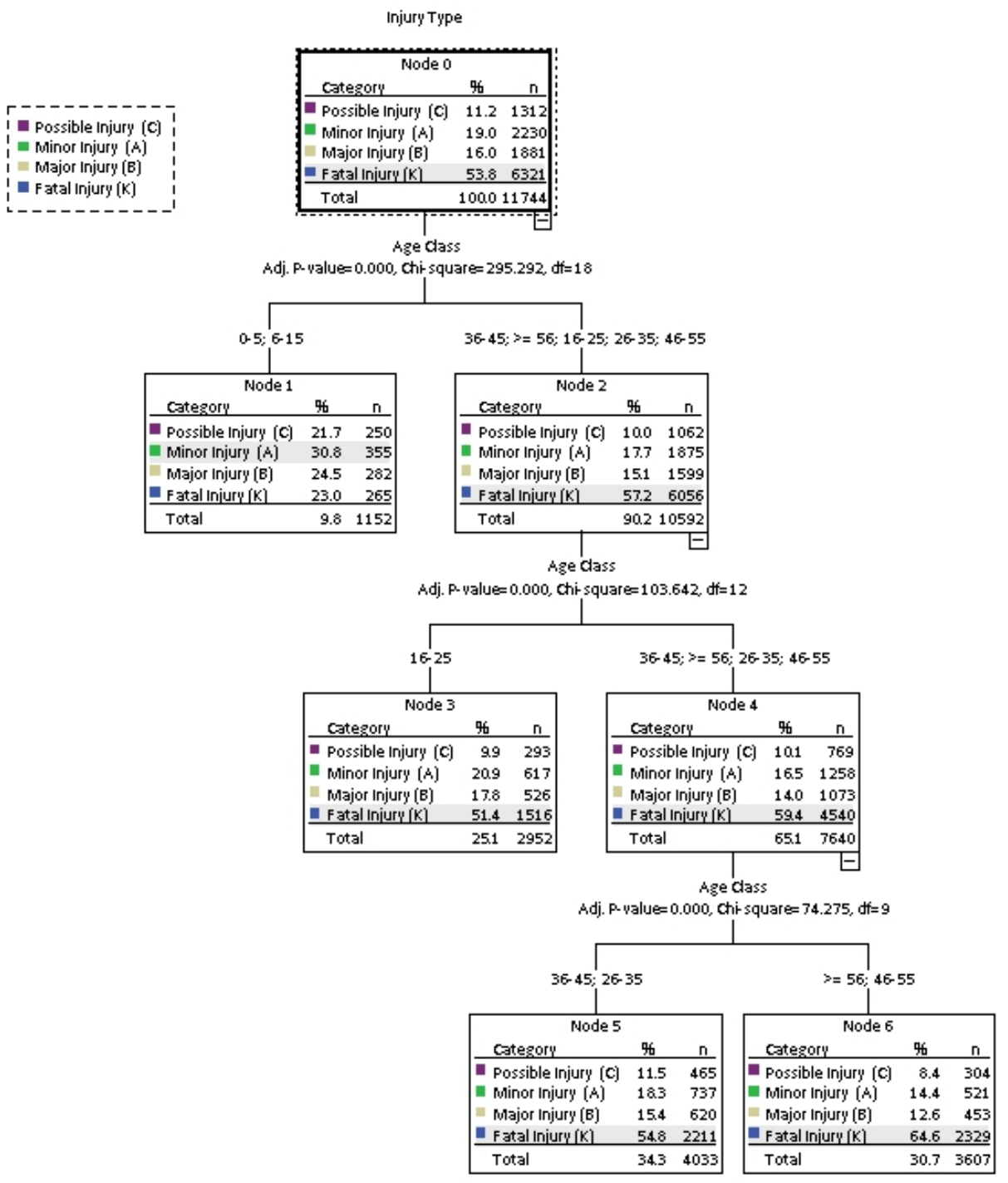

Figure 2: Difference in injury severity among different age groups 
Table 2: Pairwise comparison: Age and Ethnicity

\begin{tabular}{cccc}
\hline & Age Groups & $\mathrm{X}^{2}$ & Adj. P-value \\
\hline $0-5$ & $16-25$ & 16.22 & 0.001 \\
& $26-35$ & 18.18 & 0.000 \\
& $36-45$ & 16.58 & 0.001 \\
& $46-55$ & 20.59 & 0.000 \\
$6-15$ & $\geq 56$ & 17.43 & 0.001 \\
& $26-35$ & 10.95 & 0.020 \\
& $36-45$ & 9.67 & 0.039 \\
& $46-55$ & 13.33 & 0.005 \\
& $\geq 56$ & 10.34 & 0.027 \\
\hline Mexican & Non-Hispanics & 36.17 & 0.000 \\
Other- Hispanics & Non-Hispanics & 13.56 & 0.002 \\
\hline
\end{tabular}

In the full model (model 2), I controlled for the effect of age, sex, vehicle occupancy, restraint system/safety belt usage, and time of the year (season). Among the racial group, the odd increased by almost five times for American-Indians from what was observed in Model $1(\mathrm{OR}=4.64$; CI 0.96$22.49 ; \mathrm{p}=0.056)$. At the same time, both Asian subgroup (OR=1.31; CI $0.53-3.2 ; \mathrm{p}>0.05)$ and White $(\mathrm{OR}=1.098 \mathrm{CI} 0.76-1.58 ; \mathrm{p}>0.05)$ had the likelihood of dying in fatal RTA. At the same time, the odd of dying was higher for European Spanish and Central/South-Americans subgroups (OR= 1.64 CI 0.90-3.0) and Mexicans ( $\mathrm{OR}=1.16$; CI 0.99-1.36; $\mathrm{p}=0.063)$. 'Other' Hispanic subgroup consistently experienced significantly lower odd $(\mathrm{OR}=$ 0.66; CI 0.55-.79; $\mathrm{p}<0.05$ ) compared with non-Hispanic group (Table 3).

For the demographic groups, the odds were higher among children (6-15 yrs.), youths (16-25 yrs.) and adults (26-35 yrs.). On the other hand, the odd of dying in a fatal accident was lower for the younger children (0-15 yrs.) and older age groups (36-55) compared with reference category ( $\geq 56$ yrs.). Male occupants were more likely than female to die in a fatal accident $(\mathrm{OR}=1.082 \mathrm{CI} 0.94-1.24 ; \mathrm{p}>0.05)$. In addition, the risk increases with occupancy rate, the higher the number of people in the vehicle, the higher the odd of fatality during any accident event $(\mathrm{OR}=1.047 \mathrm{CI} 1.00-1.09 ; \mathrm{p}<0.05)$. Finally, though not significant, people are more likely to die in a fatal accident in the Fall compared with the Winter period. 
Table 3. Multi-level logistic model of fatal accident.

\begin{tabular}{|c|c|c|c|c|}
\hline & \multicolumn{2}{|r|}{ Model 1} & \multicolumn{2}{|r|}{ Model 2} \\
\hline & $\beta$ & AOR $(95 \% \mathrm{CI})$ & B & AOR $(95 \% \mathrm{CI})$ \\
\hline \multicolumn{5}{|l|}{ Race/Ethnicity } \\
\hline Other Mixed Races & 1 & 1 & 1 & 1 \\
\hline White & -0.05 & $0.95(0.71-1.27)$ & 0.09 & $1.098(0.76-2)$ \\
\hline Black & -0.349 & $0.72(0.52-0.97) \dagger$ & -0.13 & $0.876(0.59-1.3)$ \\
\hline American-Indian & 1.121 & $3.1(0.69-13.65)$ & 1.54 & $4.644(0.96-23)+$ \\
\hline Asian & -0.195 & $0.8(0.39-1.73)$ & 0.27 & $1.311(0.53-3.2)$ \\
\hline Vietnamese/Guamanian & -0.133 & $0.9(0.42-1.82)$ & 0.21 & $1.234(0.53-3)$ \\
\hline Non-Hispanics & 1 & 1 & 1 & 1 \\
\hline Mexican & 0.055 & $1.06(0.93-1.12)$ & 0.15 & $1.16(0.99-1.36) \div$ \\
\hline Puerto Rican/Cuban & -0.479 & $0.62(0.36-1.05) \ddagger$ & -0.48 & $0.62(0.31-1.24)$ \\
\hline European Spanish, CASA & -0.037 & $0.96(0.58-1.62)$ & 0.49 & $1.65(0.90-3.00)$ \\
\hline Other Hispanics & -0.779 & $0.46(0.39-0.53) \dagger$ & -0.41 & $0.66(0.55-0.79) \dagger$ \\
\hline \multicolumn{5}{|l|}{ Sex } \\
\hline Male $(\mathrm{RC}=$ Female $)$ & & & 0.079 & $1.08(0.94-1.24)$ \\
\hline \multicolumn{5}{|l|}{ Occupancy } \\
\hline Vehicle Occupancy & & & 0.046 & $1.05(1.0-1.09) \dagger$ \\
\hline \multicolumn{5}{|l|}{ Season } \\
\hline Winter & & & 1 & 1 \\
\hline Spring & & & -0.099 & $0.91(0.76-1.08)$ \\
\hline Summer & & & -0.071 & $0.93(0.79-1.10)$ \\
\hline Fall & & & 0.073 & $1.08(0.90-1.28)$ \\
\hline \multicolumn{5}{|l|}{ Safety behavior } \\
\hline Restraint (RC=Not Used) & & & -0.075 & $0.93(0.82-1.05)$ \\
\hline \multicolumn{5}{|l|}{ Age Group } \\
\hline $\mathrm{RC}: \geq 56$ & & & 1 & 1 \\
\hline $0-\overline{5}$ & & & -0.189 & $0.83(0.51-1.35)$ \\
\hline $6-15$ & & & 0.067 & $1.07(0.71-1.60)$ \\
\hline $16-25$ & & & 0.029 & $1.02(0.86-1.23)$ \\
\hline $26-35$ & & & 0.061 & $1.06(0.88-1.28)$ \\
\hline $36-45$ & & & -0.075 & $0.93(0.76-1.14)$ \\
\hline $46-55$ & & & -0.079 & $0.92(0.75-1.13)$ \\
\hline Constant & 1.014 & 2.756 & -0.063 & 0.939 \\
\hline Nagelkerk $\mathrm{R}^{2}$ & & 0.026 & & 0.019 \\
\hline H-L Test: Sig. level & & 0.099 & & 0.376 \\
\hline $\mathrm{N}$ & & 7685 & & 4374 \\
\hline
\end{tabular}

$\dagger$ sig. at $95 \%$ confidence level; $\$$ sig. at $90 \%$ confidence level; RC reference category; AOR adjusted odd ratio, CI confidence interval. CASA Central American and South American.

\section{Discussion}

This study used mixed statistical methods to examine the disparity in fatal accident among different age groups, race and ethnicity. The analyses of FARS accident data showed that more people died in fatal accident that occurred in Texas compared with those who did not die. However, many sustained severe injury compared with those who sustained major or minor injury. Relative to existing literature in terms of safety measure, use of seat 
belt was comparably lower in Texas (Wells et al., 2002). Further, Table 1 shows that Whites and people of Hispanic origin were more involved in fatal accident within the study period.

\section{- Inter-groups disparity: age groups, race and ethnicity}

Important contribution of this study to existing body of knowledge is by unveiling the cultural disparity among minority groups which have long been concealed in other studies. Previous studies have only examined disparity between Black/African-American, White Hispanics, American Indians, and non-White Hispanics or between Hispanics and non-Hispanics (Braver, 2003; Campos-Outcalt et al., 2003; Campos-Outcalt, Prybylski, Watkins, Rothfus, \& Dellapenna, 1997; Schiff \& Becker, 1996). In contrast to what have been found in previous racial/ethnic research, the model in this study predicts Asian groups, European Spanish, Central and Southern Americans have high probability of dying in a fatal accident in Texas. Before this study, there was no particular attention on European Spanish involved in fatal accident. In consistent with findings by Campos-Outcalt et al. (2003), this study found American Indians to be more at risk.

People's personality is inherently imbedded in their culture. Tao et al. (2017) showed that personal trait and driving experience influence accident risk among the Chinese group. Although, the model used in this study did not accounted for experience of a driver due to lack of variable to quantify it, it thus acknowledged its influence in the theoretical framework presented in this study. Future study should endeavour to measure this variable at lower geographical scale especially where there is cultural diversity at state level. As mentioned earlier, driving culture varies geographically over space. One typical explanation why European Spanish/CASA and Asian populations were more involved in fatal accident can be related to cultural differences and slow cultural adaptation in their new place of residence (Factor et al., 2011, 2007, 2008).

Children between the ages of 6 and 15, youths and young adult were found to be more vulnerable to fatal road accident compared with both older age groups and infants/pre-school age group (0-5). This finding corroborates the cohort study at the national level by Wolf et al. (2017). The reason why children within the ages 6 to 15 were more involved in fatal can be partly related to driver license policy (Romano, Fell, \& Voas, 2011). Texas is one of the $15 \%$ states in the United States that issue driver license to minors (Department of Motor Vehicle, 2018). A supervised type of driver license is issued to children who are 15 years, known as Minor Restricted Driver License (MRDL) compared to the minimum age of 17 years in New Jersey. This finding points to the direction of fatal road accident in childhood mortality in Texas. The primary role of accident in child and teenage 
mortality needs further clarification from different study perspective. Finally, the finding on age in the full model is inconsistent with the finding in another study that used FARS data (e.g. Bedard et al., 2002).

This study found that vehicle occupancy ratio has a negative influence on fatal accident involvement as observed in previous studies (Behnood \& Mannering, 2017; Jacobson \& Gostin, 2010; Lee \& Abdel-Aty, 2008; Simons-Morton et al., 2011; Wilson \& Stimpson, 2010). As number of occupant increases, more fatal accidents are likely to occur. Consistent with the literature, this study found that vehicle occupants that used one form of restraint system were less likely to die in a crash (Briggs et al., 2006; Han et al., 2017; Wells et al., 2002). Seat belt use continue to serve as a protective factor in road accident among fatal accident victim who did not die.

Three limitations are identified in this study. First, this study did not examine the geographic variation of fatal road accident within administrative spaces such as county or zipcode level. Understanding how fatal accident varies in a geographic space can reveal other latent factor that may be responsible for fatal accident in a particular location such as accident at intersections, in rural and metropolitan areas. Future studies should explore this opportunity in this area of accident research. Second, the study did not examine the influence of socioeconomic status, driver license status, and driving experience which could influence the results of this study. Third, lack of reliable data prevents the normalization of the estimates by crash exposure data such as miles traveled per vehicle or groups. This limitation is peculiar to other studies that have used FARS data in the past (Romano et al., 2011).

\section{Conclusion}

In conclusion, this study showed that fatal injury varies significantly among socio-cultural groups. Particularly, accident fatality was also significantly associated to younger age group, Asian and European Spanish minority groups in Texas. Race and ethnicity by themselves did not serve as predictor for the risk of dying in a fatal accident, age, sex and season are risk factors that may influence the level of vulnerability among the groups examined in this study. More public campaign should be targeted towards driving education among young drivers and most immigrants with foreign driving experience who formed the vulnerable minority groups in this study.

\section{Acknowledgement}

The author appreciates the critical comment by Dr. F.B Zhan of department of Geography, Texas State University during the presentation of the result in his Spring 2018 advanced quantitative class. Also, I thank the reviewers of the manuscript for their swift response. 


\section{References:}

1. Ang, B. H., Chen, W. S., \& Lee, S. W. H. (2017). Global burden of road traffic accidents in older adults: a systematic review and metaregression analysis. Archives of Gerontology and Geriatrics, 72, 3238.

2. Bedard, M., Guyatt, G. H., Stones, M. J., \& Hirdes, J. P. (2002). The independent contribution of driver, crash, and vehicle characteristics to driver fatalities. Accident Analysis \& Prevention, 34(6), 717-727.

3. Behnood, A., \& Mannering, F. (2017). The effect of passengers on driver-injury severities in single-vehicle crashes: A random parameters heterogeneity-in-means approach. Analytic Methods in Accident Research, 14, 41-53. https://doi.org/10.1016/j.amar.2017.04.001

4. Blincoe, L. J, Zaloshnja, T. ., \& Lawrence, B. . (2015). The Economic and Societal Impact of Motor Vehicle Crashes, 2010 (Revised)1. Annals of Emergency Medicine, 66(2), 194-196. https://doi.org/10.1016/j.annemergmed.2015.06.011

5. Braver, E. R. (2003). Race, Hispanic origin, and socioeconomic status in relation to motor vehicle occupant death rates and risk factors among adults. Accident Analysis \& Prevention, 35(3), 295309. https://doi.org/10.1016/S0001-4575(01)00106-3

6. Briggs, N. C., Levine, R. S., Haliburton, W. P., Schlundt, D. G., Goldzweig, I., \& Warren, R. C. (2005). The Fatality Analysis Reporting System as a tool for investigating racial and ethnic determinants of motor vehicle crash fatalities. Accident Analysis \& Prevention, 37(4), 641-649.

7. Briggs, N. C., Schlundt, D. G., Levine, R. S., Goldzweig, I. A., Stinson, N., \& Warren, R. C. (2006). Seat belt use among Hispanic ethnic subgroups of national origin. Injury Prevention, 12(6), 421426. https://doi.org/10.1136/ip.2006.012435

8. Campos-Outcalt, D., Bay, C., Dellapena, A., \& Cota, M. K. (2003). Motor vehicle crash fatalities by race/ethnicity in Arizona, 1990-96. Injury Prevention, 9(3), 251-256.

9. Campos-Outcalt, D., Prybylski, D., Watkins, A. J., Rothfus, G., \& Dellapenna, A. (1997). Motor-vehicle crash fatalities among American Indians and non-Indians in Arizona, 1979 through 1988. American Journal of Public Health, 87(2), 282-285.

10. Chong, S.-L., Tyebally, A., Chew, S. Y., Lim, Y. C., Feng, X. Y., Chin, S. T., \& Lee, L. K. (2017). Road traffic injuries among children and adolescents in Singapore-Who is at greatest risk? Accident Analysis \& Prevention, 100, 59-64. 
11. Daniel, J. R., Bladikas, A., \& Curley, J. (2007). Factors influencing seat belt usage rate for blacks and Hispanics. TRANSPORTATION RESEARCH RECORD, (2009), 74-81.

12. Department of Motor Vehicle. (2018). Apply for a Texas Teen Driver's License. Retrieved April 30, 2018, from https://www.dmv.org/tx-texas/teen-drivers.php

13. Elias, W., Blank-Gomel, A., Habib-Matar, C., \& Shiftan, Y. (2016). Who are the traffic offenders among ethnic groups and why? Accident Analysis \& Prevention, 91, 64-71. https://doi.org/10.1016/j.aap.2016.02.022

14. Factor, R., Kawachi, I., \& Williams, D. R. (2011). Understanding high-risk behavior among non-dominant minorities: A social resistance framework. Social Science \& Medicine, 73(9), 1292-1301.

15. Factor, R., Mahalel, D., \& Yair, G. (2007). The social accident: a theoretical model and a research agenda for studying the influence of social and cultural characteristics on motor vehicle accidents. Accident; Analysis and Prevention, 39(5), 914-921. https://doi.org/10.1016/j.aap.2006.12.015

16. Factor, R., Mahalel, D., \& Yair, G. (2008). Inter-group differences in road-traffic crash involvement. Accident Analysis \& Prevention, 40(6), 2000-2007.

17. Factor, R., Williams, D. R., \& Kawachi, I. (2013). Social Resistance Framework for Understanding High-Risk Behavior Among Nondominant Minorities: Preliminary Evidence. American Journal of Public Health, 103(12), 2245-2251. https://doi.org/10.2105/AJPH.2013.301212

18. Hamdan, H. (2013). Racial/Ethnic Differences in Fatality Rates from Motor Vehicle Crashes: An Analysis from a Behavioral and Cultural Perspective. Retrieved from https://scholar.google.com/scholar

19. Han, G.-M., Newmyer, A., \& Qu, M. (2017). Seatbelt use to save money: Impact on hospital costs of occupants who are involved in motor vehicle crashes. International Emergency Nursing, 31, 2-8.

20. Hilton, J. (2006). Race and ethnicity in fatal motor vehicle traffic crashes 1999 - 2004: (731862011-001) [Data set]. American Psychological Association. https://doi.org/10.1037/e731862011-001

21. Insurance Institute for Highway Safety (IIHS), H. (2002). Racial disparities in safety belt use. Retrieved February 23, 2018, from http://www.iihs.org/iihs/sr/statusreport/article/37/2/2

22. Jacobson, P. D., \& Gostin, L. O. (2010). Reducing distracted driving: regulation and education to avert traffic injuries and fatalities. JAMA, 303(14), 1419-1420. 
23. Lee, C., \& Abdel-Aty, M. (2008). Presence of passengers: does it increase or reduce driver's crash potential? Accident Analysis \& Prevention, 40(5), 1703-1712.

24. Lu, Y., \& Davidson, A. (2017). Fatal motor vehicle crashes in Texas: needs for and access to emergency medical services. Annals of GIS, 23(1), 41-54.

25. Ma, P., Hussain, N., \& Abbe, M. (2017). An examination of trafficrelated traumatic injuries among children at a Level-1 pediatric trauma center, 2005-2014. Journal of Trauma and Acute Care Surgery, 83(5S), S233-S239.

26. Onwuachi-Saunders, C., \& Hawkins, D. F. (1993). Black-white differences in injury race or social class? Annals of Epidemiology, 3(2), 150-153.

27. Romano, E., Fell, J., \& Voas, R. (2011). The role of race and ethnicity on the effect of graduated driver licensing laws in the United States. In Annals of Advances in Automotive Medicine/Annual Scientific Conference (Vol. 55, p. 51). Association for the Advancement of Automotive Medicine.

28. Rupp, J. D., Flannagan, C. A., Leslie, A. J., Hoff, C. N., Reed, M. P., \& Cunningham, R. M. (2013). Effects of BMI on the risk and frequency of AIS 3+ injuries in motor-vehicle crashes. Obesity, $21(1)$.

29. Schiff, M., \& Becker, T. (1996). Trends in motor vehicle traffic fatalities among Hispanics, non-Hispanic whites and American Indians in New Mexico, 1958-1990. Ethnicity \& Health, 1(3), 283291.

30. Simons-Morton, B. G., Ouimet, M. C., Zhang, Z., Klauer, S. E., Lee, S. E., Wang, J., ... Dingus, T. A. (2011). The effect of passengers and risk-taking friends on risky driving and crashes/near crashes among novice teenagers. Journal of Adolescent Health, 49(6), 587593.

31. Sümer, N. (2003). Personality and behavioral predictors of traffic accidents: testing a contextual mediated model. Accident Analysis \& Prevention, 35(6), 949-964.

32. Tao, D., Zhang, R., \& Qu, X. (2017). The role of personality traits and driving experience in self-reported risky driving behaviors and accident risk among Chinese drivers. Accident Analysis \& Prevention, 99, 228-235.

33. Tseng, W.-S., Nguyen, H., Liebowitz, J., \& Agresti, W. (2005). Distractions and motor vehicle accidents: Data mining application on fatality analysis reporting system (FARS) data files. Industrial Management \& Data Systems, 105(9), 1188-1205. 
34. Wells, J. K., Williams, A. F., \& Farmer, C. M. (2002). Seat belt use among African Americans, Hispanics, and Whites. Accident; Analysis and Prevention, 34(4), 523-529.

35. Wilde, G. J. (1982). The Theory of Risk Homeostasis: Implications for Safety and Health. Risk Analysis, 2(4), 209-225. https://doi.org/10.1111/j.1539-6924.1982.tb01384.x

36. Wilde, G. J. (2009). Risk homeostasis: theory, evidence and practical implications. Invited lecture at the Road Safety Advance Course, Department of Civil Engineering, University of Palermo, Italy.

37. Wilson, F. A., \& Stimpson, J. P. (2010). Trends in fatalities from distracted driving in the United States, 1999 to 2008. American Journal of Public Health, 100(11), 2213-2219.

38. Wolf, L. L., Chowdhury, R., Tweed, J., Vinson, L., Losina, E., Haider, A. H., \& Qureshi, F. G. (2017). Factors associated with pediatric mortality from motor vehicle crashes in the United States: a state-based analysis. The Journal of Pediatrics, 187, 295-302.

39. World Health Organization [WHO]. (2017). The top 10 causes of death. Retrieved April 23, 2018, from http://www.who.int/mediacentre/factsheets/fs310/en/ 